\title{
O que pensam sobre o erro matemático estudantes do terceiro ano do Ensino Médio?
}

\author{
André Gustavo Oliveira da Silva \\ Doutorando, UEL/PPG em Ensino de Ciências e Educação Matemática \\ andregutoiap@yahoo.com.br
}

\section{Marinez Meneghello Passos}

Professor, UEL/Departamento de Matemática

marinezmp@sercomtel.com.br

\section{Rosana Figueiredo Salvi}

Professora, UEL/Departamento de Geociências

rosana.salvi@uel.br

\section{Resumo}

Neste artigo lançamos mão dos procedimentos e recursos apresentados pela análise de conteúdo para investigarmos a percepção de alunos do terceiro ano do Ensino Médio sobre o erro. O processo ocorreu por meio do preenchimento de quatro "relatórios de reflexão sobre os erros" (instrumento utilizado na intervenção após a realização da prova bimestral) com a expectativa de estimular a (re)construção do conhecimento matemático tomando o erro como ponto de partida. Desse processo analítico elaboramos nossas compreensões, sobre as ideias demonstradas pelos alunos em seus registros, a partir de um conjunto de textos elaborados com base nessas leituras. Destacamos o potencial inerente ao erro quando usado como estratégia motivadora para o aprendizado, a forte carga emocional atrelada ao erro e as questões desafiadoras que a leitura do 'subjacente', por meio da análise de conteúdo, trouxeram à tona.

Palavras-chave: Erro. Relatório de Reflexão sobre os Erros. Análise de Conteúdo.

\section{What high school students think about mathematical error?}

\begin{abstract}
In this article we utilized the resources provided by content analysis to investigate the perceptions of the students of the third year of high school about error. The process of reelaboration of those errors by filling a sequence of four "reports on the reflection on the errors" (instrument used in the intervention after the exam bimonthly) with the hope of stimulating (re)construction of mathematical knowledge by taking the error as a starting point. From this analytic process we built understandings on the perception demonstrated by the students on their records of several texts created on basis of these "readings". We highlight the inherent potential of error when used as a motivative strategy to learning, the emotional burden implied in committing errors and the challenging issues related to the subjacent reading enabled by analysis content, emerged.
\end{abstract}

Keywords: Error. Report about reflection on error. Content analysis. 


\section{Considerações iniciais}

O aproveitamento do erro como um aliado ao processo de ensino e aprendizagem da Matemática, por meio de estratégias adequadas que promovam a reflexão, a confrontação e a superação do mesmo tem sido bastante discutido e apreciado no âmbito escolar. Cury e Konzen (2007) argumentam que esta é uma tendência emergente na Educação Matemática e que está permeando várias dissertações, teses e comunicações.

E na ótica do estudante? Sob que perspectiva ele vê o erro? O erro pode ser visto e assumido como um aliado ao processo do aprendizado?

Esse artigo traz parte dos dados coletados e que foram submetidos aos procedimentos da análise de conteúdo, fundamentada em Bardin (2004) e Moraes e Galiazzi (2007). Nesta proposta, aqui materializada, optamos por um recorte das informações pertinentes a uma pesquisa mais ampla, que estamos desenvolvendo sobre o erro construtivo em avaliações normativas, e que tem por objetivo geral investigar as percepções finais e as alterações dessas percepções dos estudantes do Ensino Médio referentes ao erro (depois de passarem por todas as etapas da intervenção proposta pela pesquisa - em sua amplitude - no decorrer do ano de 2010).

Segundo o dicionário de Filosofia, "percepção designa uma operação determinada do homem em suas relações com o ambiente" (ABAGNANO, 2007). Assumimos tal termo por termos o propósito de observar e registrar evidências que sinalizem a possível e gradual mudança na forma de encarar o erro matemático à medida que realiza as atividades planejadas e propostas com vistas a tornar o erro observável e convertê-lo em ponto de partida para o aprendizado.

Na sequência apresenta-se uma breve argumentação sobre a relevância do erro no processo de ensino e de aprendizagem da Matemática; alguns dados obtidos da pesquisa de campo; o movimento de categorização a partir do tratamento dos dados, propiciados pela análise de conteúdo; as análises e as interpretações obtidas com o fim de compreender o significado das informações contidas no bojo dos dados coletados.

\section{O erro como aliado ao processo de aprendizagem da Matemática}

Muitos pesquisadores em Educação corroboram com a idéia de se usar o erro como um aliado ao processo do aprendizado, dentre estes Dalto e Buriasco (2009), Buriasco et al. (2009), Cury (2007), Cury e Konzen (2007), Silva e Buriasco (2005), Esteban (2002), Bertoni (2000), La Taille (1997), Luckesi (1996), Davis e Espósito (1991).

É consensual entre pesquisadores e educadores que o erro contém informações relevantes sobre o aprendizado dos estudantes e tornar-se revelador, quando analisado 
de forma criteriosa podendo, ainda, promover ganhos significativos ao aprendizado caso seja, adequadamente, investigado e utilizado como aliado ao processo.

Com a finalidade de formar um patamar teórico inicial que norteasse nossas reflexões fizemos uma revisão bibliográfica pinçando informações, que se evidenciam e são consideradas relevantes para o propósito dessa investigação.

Perrenoud considera o erro uma ferramenta para ensinar, "um revelador dos mecanismos de pensamento do aprendiz" (PERRENOUD, 2000).

Segundo Kistemann (2006), o erro permite um mapeamento do aprendizado dos alunos, revelando "acidentes geográficos" que auxiliam professor e aluno descobrirem melhores formas de assimilar, acomodar e regular os conteúdos.

Para Luchesi (1996) o erro pode ser considerado uma forma de expressar o esforço de alguém que busca algo; e nessa busca pode ser bem ou mal sucedido. Há que se observar que o erro, como manifestação de uma conduta não aprendida, decorre do fato de que há um padrão já produzido e ordenado que indica a direção do avanço da aprendizagem do aluno e, por conseguinte, a compreensão do desvio, possibilitando sua correção inteligente.

Ao considerar essas colocações teóricas, observamos algo em comum: são unânimes em afirmar que o erro possui grande importância dentro do processo de ensino e de aprendizagem.

Com relação à importância de inserir o erro no contexto do ensino e da aprendizagem, destacamos a seguir o que nos revelam essa caracterização, que contribui com o objetivo desta investigação e da interpretação de seus dados.

Buriasco (2000), em concordância com grande parte dos educadores matemáticos, defende que o aluno deveria ser exposto ao erro, ser encorajado a detectar e demonstrar o que está errado ao invés de ser protegido do mesmo.

Macedo (1995) afirma que o aluno, ao reinterpretar seu erro, revisando suas idéias e ações, pode alcançar a compreensão que lhe permite alterar o fazer. A análise do erro, por parte do aluno, servirá como subsídio para reorientá-lo e conduzi-lo a perceber onde e o porquê errou, percebendo sua dificuldade, analisando-a e buscando alternativas para superá-la.

Silva e Buriasco (2005), educadoras matemáticas e pesquisadoras da produção escrita dos alunos em provas, afirmam que a partir da análise dos registros é possível realizar uma intervenção que de fato contribua para o desenvolvimento dos alunos. Sugerem uma intervenção informada e ajustada a serviço da regulação do processo de ensino e de aprendizagem.

Enquanto pesquisadores ainda não temos uma definição própria para o erro, porém ancorados nas leituras realizadas, em compreensões advindas de nossa práxis e de processo investigativo maior, podemos vislumbrar - no sentido de ainda não 
ter definição precisa para o termo - o erro como um modo peculiar do aprendiz expressar seu raciocínio, podendo assumir caráter provisório e contribuir para a (re) construção do conhecimento matemático quando observado e conflitado cognitivamente por meio de atividades planejadas, atuando como um deflagrador de novas situações de aprendizagens.

Na busca de promover uma intervenção informada e ajustada, como sugerem Silva e Buriasco (2005), coloca-se em prática uma proposta em que os estudantes do Ensino Médio têm a oportunidade de (re)construir seu 'percurso' para o aprendizado do conteúdo matemático por meio de momentos de reflexão.

Esclarecemos que quando nos referimos ao termo (re)construção o fazemos no sentido de que temos percebido, em nossa investigação, a ocorrência de duas situações: a primeira em que os estudantes se dão conta de que precisam aprender um conceito novo, que lhes passou despercebido no momento da aprendizagem e vão à procura do que precisam - a isto estamos designando de construção; uma segunda situação se dá quando necessitam resgatar um conhecimento não revisado ou não lembrado no momento em que responderam a questão; com isso justificamos o prefixo "re".

Com isto pretendemos desafiá-lo a rever a forma como aprendeu e corrigindo 'possíveis desvios' que os levaram a errar na resolução da atividade proposta. Este procedimento ocorre sempre após a realização e a devolutiva das provas escritas, durante o ano letivo.

\section{Erro: parceiro ou inimigo? O que revelou a pesquisa?}

A questão motivadora do que apresentamos neste artigo é a pergunta de número 5 (que compõem um questionário com seis questões) e que traz a seguinte indagação - Como você vê o erro? Como parceiro ou inimigo do aprendizado? Justifique sua resposta e dê exemplos que reforcem seus argumentos.

Desse processo de coleta foram obtidas diferentes respostas dos estudantes. No Quadro 1 estão apresentadas de forma quantitativa as percepções iniciais registradas por eles, contudo, na continuidade, avançamos na direção de compreender o que essas respostas - listadas inicialmente desta forma - trazem em suas argumentações explicativas e justificadas por cada um.

\section{Quadro 1 - Respostas obtidas à questão: Como você vê o erro? Como parceiro ou inimigo do aprendizado?}




\begin{tabular}{llll}
\hline Respostas & $\begin{array}{l}\text { Frequência } \\
\text { absoluta }\end{array}$ & Alunos depoentes & $\begin{array}{l}\text { Frequência em } \\
\text { percentagem }\end{array}$ \\
\hline Parceiro & 26 & A12, A13, A14, .., A37 & 70,27 \\
\hline Inimigo & 1 & A4 & 2,70 \\
\hline Ambos & 8 & A1, A5, A6, A7, A8, A9, & 21,62 \\
\hline Nenhum dos dois & 1 & A10, A11 & 2,70 \\
\hline Depende & 1 & A2 & 2,70 \\
\hline Totais & $\mathbf{3 7}$ & A3 & $\mathbf{1 0 0 , 0 0}$ \\
\hline
\end{tabular}

Fonte: Dados primários provenientes de questionário.

De imediato o que nos chama atenção é o fato de terem surgido cinco tipos de respostas, mesmo estando a pergunta restrita a duas possibilidades. O que consideramos positivo, pois revela a possibilidade de expressarem o que pensam e como pensam a esse respeito - sem a limitação do que foi indicado no questionário.

Em uma análise restrita, somente considerando à tabulação dos dados, é possível verificar que uma expressiva maioria (70\%) indica o erro como parceiro do aprendizado. A compreensão primeira que temos é que esses alunos agregam algum tipo de vantagem e de valor ao seu processo formativo quando erram. Cabe relembrar que estamos analisando o erro - em uma situação específica - em um processo compreendido por várias etapas e, dentre elas, uma em que o estudante tem a oportunidade de refletir e re-elaborar o erro cometido na prova escrita.

Um dos estudantes classificou o erro apenas como inimigo. O que também nos chama a atenção, pois contraria a tendência dos dados. Uma discrepância talvez? Um caso especial que merece um estudo de caso? Certamente são hipóteses que podem frutificar, todavia estaremos interpretando suas justificativas e verificando o sentido dessa escolha.

Oito alunos vêem no erro as duas possibilidades: pode ser tanto um parceiro como um inimigo, dependendo do contexto, do momento em que se apresenta e do tipo de intervenção proposta a partir de sua manifestação.

Um dos alunos realiza seus registros afirmando que o erro não é nem parceiro nem inimigo é "simplesmente um tipo de aprendizado" - observem a relação com

1 Este código está relacionado a cada aluno que fez parte da pesquisa - A indica aluno - e o número que o acompanha representa cada um dos 37 depoentes. 
o aprendizado - não caberia aqui o termo 'parceiro'? Contudo, o que nos revelará a justificativa deste aluno?

E por fim temos um deles que se posiciona da seguinte maneira: "se toda prova me desse o direito de refletir sobre meus erros, poderia aprender com eles", e em seu depoimento não indica qualquer resposta à questão que apresenta para o erro os adjetivos - parceiro ou inimigo.

Diante dessa leitura, colocamo-nos em outro movimento investigativo, a busca por compreensão do que os posicionamentos indicados podem significar para cada um dos depoentes, ou seja, o que essas respostas apresentadas representam e como elas estão justificadas. Para isso adotamos os procedimentos indicados pela análise de conteúdo, começando pela organização dos questionários coletados até a comunicação de nossas apreensões relativas ao fenômeno em questão.

\section{A metodologia da análise de conteúdo}

Realizar uma análise textual das respostas registradas pelos alunos implica interpretar os enunciados produzindo um metatexto, que é composto por textos descritivos e interpretativos usando como referência as unidades de análise que foram construídas na intenção de explicitar novas relações. Para Moraes e Galiazzi (2007) esse movimento constitui-se a partir de algo importante que o pesquisador tem a dizer sobre o fenômeno que investigou, um "argumento aglutinador" resultante da familiaridade com os dados que investiga.

Por se tratar de um movimento produtivo do pesquisador, há que se considerar, portanto, a subjetividade do processo e consequentemente passível de crítica e aperfeiçoamento constante devido a sua permanente incompletude.

A análise de conteúdo pode ser compreendida, segundo Moraes e Galiazzi (2007) como um processo auto-organizado de construção e de compreensões em que novos entendimentos emergem a partir de uma sequência recursiva de três componentes: a desconstrução dos textos do corpus ${ }^{2}$, seguida pela unitarização; o estabelecimento de relações entre os elementos unitários, que converge à categorização; o captar o emergente em que a nova compreensão é comunicada por meio de um metatexto.

No processo de desconstrução destroem-se as ordenações lógicas expostas pelos autores - neste caso os depoentes - alunos do Ensino Médio, para, a partir do caos, estabelecer novas relações tendo por base o material fragmentado. Estas

2 O conjunto de documentos tidos em conta para serem submetidos aos procedimentos analíticos (BARDIN, 2004, p.90). 
relações surgem quando ocorre uma intensa impregnação com o objeto da pesquisa e são desencadeadas por meio do envolvimento aprofundado e prolongado na busca de um processo que migra da leitura do manifesto - o que está diretamente posto e, geralmente leva às interpretações comuns, para a leitura do latente - que vai além do transcrito, alcançando a profundidade dos sentidos latentes.

O material fragmentado será submetido a leituras flutuantes com o propósito de que a partir dessas leituras descompromissadas emirjam novas compreensões. Serão feitas tantas leituras quantas forem necessárias a fim de que ocorra uma impregnação intensa com o fenômeno em estudo, favorecendo um envolvimento consciente e inconsciente na expectativa da emergência de novas compreensões.

A constante comparação das unidades fragmentadas no primeiro movimento conduz ao segundo: agrupamento de elementos semelhantes, num processo de organização intuitiva, comandado por "flashes fugazes" (MORAES e GALIAZZI, 2007), insights repentinos e globalizados que auxiliam esse movimento de reorganização chamado de unitarização.

A unitarização procura identificar e destacar aspectos originais e criativos dos textos que se propõe a analisar, o que requer um movimento intenso e perspicaz no qual a intuição é vital para a emergência do novo. Sugere a migração da ordem para a desordem, do consciente para o inconsciente, na expectativa de que novas organizações emirjam do processo.

Unitarização, segundo Moraes e Galiazzi (2007) é um processo de desconstrução dos textos do corpus com o objetivo de diferenciar e identificar elementos unitários que o constituem. É um exercício analítico de desmembramento dos enunciados constitutivos, pela busca de detectar elementos de sentido que não estão evidentes em uma primeira leitura.

Bardin (2004) qualifica o processo de unitarização como desafiante, pois envolve aspectos psicológicos e linguísticos em que o que se procura é o conhecimento que está para além das palavras sobre as quais se debruça. Um exercício de leitura do que está implícito nos dados.

Após este momento, segue-se a organização das categorias num esforço consciente e racionalizado. É a categorização dos dados. Uma etapa integrante do processo de análise de conteúdo e corresponde a um ordenamento das unidades de análise, ou seja, um movimento classificatório a fim de viabilizar a construção de estruturas compreensivas do fenômeno investigado. É um processo de classificação recursivo e iterativo.

Bardin (2004) argumenta (e verificamos isto nesta prática) que a análise de conteúdo é arborescente, isto é, durante o processo técnicas e interpretações atraem-se e o movimento pode ganhar uma dimensão não prevista inicialmente. 


\section{A metodologia da pesquisa e a coleta dos dados}

A pesquisa realizada, segundo Lüdke e André (1986), caracteriza-se como análise documental, pois pretendemos construir compreensões procedendo com o tratamento analítico dos dados obtidos a partir dos relatórios redigidos pelos estudantes. Possui cunho qualitativo, uma vez que a ênfase está no processo e não somente nos resultados, a análise dos dados ocorre de forma indutiva e a opinião dos estudantes é de grande relevância.

Os dados utilizados nesta pesquisa, como indicado anteriormente, foram selecionados a partir de um recorte realizado em uma quantidade de informações bem maior e que constituem a matéria prima de uma investigação mais ampla e que está sendo realizada com estudantes de três turmas de terceiro ano do Ensino Médio. A investigação - em suma e de forma generalizada - tem como foco usar o erro cometido em avaliações normativas como agente deflagrador de situações de aprendizagem do conteúdo matemático.

No decorrer dos seis anos nos quais inserimos em nossa práxis o relatório de reflexão sobre os erros como forma de intervenção na qual o erro torna-se alvo de reflexão e retomada para a (re)construção do conhecimento temos observado algumas manifestações, por parte dos estudantes, que nos servem como feedback e justificam a tomada de dados presentes neste artigo.

Podemos citar situações que denotam 'sinal verde', isto é, indicam que estamos indo na direção certa, que a proposta é frutífera e situações que denotam 'sinal vermelho' - a atividade não alcançou o objetivo proposto para alguns.

Seja qual for a situação, acreditamos que um procedimento investigativo é sempre bem vindo e oportuno na busca de melhor compreensão do fenômeno, enquanto proposta interventiva com vistas no aprendizado.

Observamos e registramos durante o processo falas e atitudes que expressavam otimismo quanto ao procedimento adotado e outras que traduziam negativismo por parte dos estudantes; e percebíamos, em alguns, certa mudança quanto à forma de encarar o erro. Havia, também, o interesse de nossa parte em saber se a intervenção que adotamos era adequada ou não aos nossos objetivos. Com este propósito elaboramos, um questionário com seis questões.

Todos os estudantes que no decorrer do ano de 2010, em quatro momentos distintos - um a cada bimestre - aderiram voluntariamente à proposta de preencher o relatório de reflexão sobre os erros cometidos na prova escrita, responderam ao questionário. Foram trinta e sete estudantes num universo de cento e vinte alunos dos terceiros anos do Ensino Médio.

O preenchimento do questionário de coleta de dados ocorreu após a devolutiva da prova escrita do $4^{\circ}$ bimestre. Como de costume os relatórios de reflexão sobre os 
erros eram disponibilizados no mesmo dia da devolução da prova. Nesta ocasião anexamos o questionário e, em princípio, todos os que se dispuseram a preencher o relatório de erros o recebeu. No tempo aprazado para a entrega do relatório de reflexão sobre os erros - via de regra uma semana - a entrega do questionário se deu simultaneamente.

A primeira questão, de cunho informativo, visava distinguir quantos relatórios de reflexão sobre os erros o estudante havia feito no ano - uma vez que nosso objetivo era trabalhar somente com os registros daqueles que haviam preenchido todos os relatórios.

A segunda questão solicitava que assinalassem em ordem de importância o que viesse à mente quando pensam na palavra 'erro'.

A terceira e a quarta eram pertinentes ao processo de execução do preenchimento do relatório relativo aos erros.

A quinta questão interpelava o estudante a respeito do que o erro representava naquele momento: parceiro ou inimigo?

A sexta questão solicitava que desenvolvesse uma narrativa, por escrito, a respeito do erro, tendo por mote a seguinte frase: "o erro, conscientemente elaborado, possibilita a oportunidade de revisão e avanço na aprendizagem” (LUCHESI, 1996).

\section{O 'Relatório de Reflexão sobre os Erros'}

A forma de como lidar com o erro representa um permanente desafio para o professor. A começar pela maneira que o concebe. Também na medida em que precisa promover uma atividade que mobilize o estudante neste processo de exposição ao seu erro a fim de que tome consciência desse erro e encontre meios de superação.

Quem de nós, em nosso sistema tradicional de avaliação, já não fez uma prova escrita e ficou ansiando por saber exatamente o que errou, o porque errou ou o que faltou fazer para acertar a questão proposta?

É provável que muitas vezes retivemos essa dúvida na expectativa de saná-la em uma próxima oportunidade até que outros interesses mais imediatos se interpõem e acabamos por não fazê-lo. A proposta da implantação do relatório de reflexão sobre os erros tem também esta expectativa, mas sobretudo procura oportunizar ao estudante descobrir, refletir e escrever sobre seus erros com o intuito final de promover um avanço em seu aprendizado.

Em geral lidávamos com os erros cometidos pelos estudantes nas provas escritas, fazendo a correção da prova na lousa, mas percebíamos a ocorrência de alguns fatores que sinalizavam que tal procedimento era limitado em sua eficácia. Dentre estes citamos: 
(a) desinteresse da maioria da turma durante a resolução das questões, pois seu foco estava voltado em saber o resultado quantificado pela nota e estabelecer comparações com os pares do que no aprendizado do conteúdo;

(b) diferentes reações que variavam desde a euforia pelo bom desempenho até manifestações de emoções negativas por um mal resultado o que dificultava a condução da aula num ambiente com tal diversidade de humor;

(c) quando se elaborava diferentes modelos de prova não havia tempo suficiente para fazer a correção de todos os modelos;

(d) Embora houvesse perguntas e manifestações de dúvidas por parte de uns poucos, muitos dos que copiavam a resolução o faziam de forma passiva o que não evidenciava a existência de uma reflexão necessária para compreensão e superação do erro.

O relatório de reflexão sobre os erros focaliza as questões nas quais o estudante apresentou algum tipo de erro ou, simplesmente, não apresentou resolução. É exigido que o enunciado de cada questão seja copiado antes de iniciar a resolução.

Este relatório passou por várias reformulações e sua versão última foi submetida à apreciação e crítica aos componentes do grupo de estudos multidisciplinares IFHIECEM - Investigações em Filosofia e História da Ciência, Educação em Ciências e Matemática - que tem reuniões semanais no campus da Universidade Estadual de Londrina. O grupo conta a coordenação de duas professoras doutoras da universidade e possui vinte e um participantes, dentre os quais dezoito estão cursando pós-graduação e atuam como professores nas áreas de Biologia, Física, Química, Matemática e Geografia.

Para o preenchimento do relatório o estudante pode pesquisar nos livros, nas anotações de aula, discutir com os colegas, recorrer à monitoria, assistir vídeos-aula disponíveis e, ainda, contar com dicas do professor nos plantões de dúvida, ou seja, é necessário que se mobilize e busque os meios necessários para realizar a atividade.

Neste relatório ele responderá a três questões: (i) qual a lógica do erro? (ii) explicar, redigindo um texto detalhado, como se resolve a questão de forma correta (iii) apresentar a resolução da questão de forma correta. Comentamos, a seguir, sobre o que pretendemos com cada etapa.

\section{(i) Qual a lógica do erro?}

Cabe esclarecer que temos observado três situações de respostas que ocorrem nas provas escritas que fazem com que a questão seja assinalada como errada: (a) respostas que apresentam resolução a partir de 'hipóteses', construídas pelos estudantes 
de forma equivocada, porém apresentam alguma lógica; (b) respostas incompatíveis com o enunciado revelando incompreensão do mesmo ou por não conhecimento do conteúdo em questão, mas ainda assim respondem para não deixar em branco, (c) ausência de resposta, sem tentativa de resolução.

Nossa expectativa é que diante da situação (a) o estudante explicite de que maneira pensou, a hipótese que usou para construir aquele raciocínio a fim de perceber em que momento se desviou do ideal, tornando observável o motivo do erro. Baldino e Cabral (1999) pesquisadores que trabalharam a re-elaboração por meio da pedagogia da assimilação solidária, defendem a idéia de que é necessário "pedir ao aluno para explicar o que fez" a fim de que 'enxergue' uma saída.

Diante das situações (b) e (c), mesmo que não se tratando de um erro construtivo, pois este revela a forma de pensar provisória do estudante podendo ser o ponto de partida para a re-elaboração de um conceito, pretendemos oportunizar um momento de introspecção em que possa tornar claro a si mesmo que possuí potencial para apresentar um rendimento melhor e comprometer-se de forma mais efetiva, pois muitas vezes a resposta é: "não fiz porque não estudei".

\section{(ii) Explicar, redigindo um texto detalhado, como se resolve a questão de forma correta.}

Baldino e Cabral (1999) argumentam que o grande desafio é convencer o estudante que a (re)construção do novo conhecimento lhe é necessária e isto pode ser alcançado quando percebe que: (1) com seus instrumentos atuais não pode dar conta da atividade proposta; (2) ao agregar novos conceitos ou simplesmente reforçar conhecimentos que esqueceu poderá alcançar o êxito, (3) o(s) novo(s) conceito(s) está(ão) ao alcance de sua capacidade. Essa etapa é a mais desafiadora. Requer uma combinação de habilidades, muitas vezes, não desenvolvida pelos estudantes. Dentre as habilidades - até agora percebidas - relacionamos: (a) tornar claro como faz a 'ponte' entre o que o enunciado pede e o procedimento escolhido para resolução; (b) explicitar sua forma de pensar quanto ao procedimento escolhido na abordagem inicial do problema; (c) descrever, passo a passo seu raciocínio. Esse procedimento favorece a organização na forma de um mapeamento das estratégias empregadas na resolução; (d) fazer uma auto-avaliação tácita após ter 'conseguido' resolver a questão que, em princípio, parecia-lhe "de outro mundo" ou "um bicho de sete cabeças".

\section{(iii) Apresentar a resolução da questão de forma correta.}

Com esta colocação temos a intenção de fomentar uma atitude em que o estudante busque informações suficientes e necessárias para responder a questão proposta. Usamos como aliado o fato de tratar-se de uma prova, o que reforça a necessidade 
da busca, pois, em geral, as avaliações escrita são abordadas com seriedade por esses estudantes do Ensino Médio e que se encontram às vésperas dos vestibulares.

Quando as provas corrigidas são entregues aos estudantes, é proposto a eles (todos) o desafio do preenchimento de um relatório de reflexão sobre erros - instrumento adotado pelo professor com vistas a tornar o erro observável e promover sua superação. Posteriormente, é realizada uma prova substitutiva, prevista no regimento, para os estudantes que obtiveram nota inferior a seis.

Diante deste contexto passamos na continuidade a apresentar a sistematização e interpretação das informações coletadas para o desenvolvimento desta investigação.

\section{As unidades de análise, o movimento de categorização e algumas interpretações}

A construção das unidades de análise e o movimento de categorização ocorreram mediante dois processos interpretativos e subsequentes - o primeiro - após a desconstrução do texto e ao aplicarmos alguns dos procedimentos metodológicos pertinentes à análise de conteúdo. Esse processo foi sistematizado, somente, depois de sucessivas idas e vindas aos fragmentos que continham as respostas justificadas e exemplificadas dos estudantes e, ainda, fazendo uso de um aplicativo do Windows - a planilha eletrônica Excel - como ferramenta para a busca de afinidades entre as informações contidas nos registros dos alunos (que foram copiados por meio de digitação dos questionários). Desse movimento foram elaboradas as unidades de análise, que chamaremos de imediatas (pois estão como os alunos as descreveram ou de uma forma muito semelhante com os registros), apresentadas no Quadro 2.

Essa primeira organização e classificação é o resultado de um processo reflexivo, amparado em possibilidades de agrupamento de características linguísticas e semânticas comuns e de hipóteses elaboradas durante as leituras iniciais, e que seguem uma ordenação lógica das semelhanças percebidas nos textos.

\section{Quadro 2 - Unidades de análise imediatas.}

\begin{tabular}{ll}
\hline Unidades de análise & Alunos depoentes \\
\hline Promove reflexão. & A4, A25, A26 \\
\hline Promove mobilização. & A1, A2, A5, A9, A23, A24, A26, A34 \\
\hline Gera emoção negativa. & A2, A5, A16, A34 \\
\hline O erro como hipótese a ser rejeitada. & A1, A5, A14, A32 \\
\hline Conscientização ("tenho que estudar”). & A6, A16, A20 \\
\hline
\end{tabular}




\begin{tabular}{ll}
\hline & $\begin{array}{l}\text { A1, A3, A13, A17, A18, A21, A22, } \\
\text { A23, A24, A26, A28, A29, A32, A35, } \\
\text { A36, A37 }\end{array}$ \\
\hline Enfase no resultado ("melhorar a nota"). & A7, A9, A10, A16, A31, A34 \\
\hline $\begin{array}{l}\text { Possibilita enxergar e agir conscientemente sobre a } \\
\text { causa do erro. }\end{array}$ & A8, A15, A18 \\
\hline Motivação para saber a causa do erro. & A13, A23 \\
\hline O erro como uma oportunidade. & A27, A15 \\
\hline Uso de "chavão". & A29, A33 \\
\hline Transcendência: "linkou" com a vida. & A15, A30, A35 \\
\hline
\end{tabular}

Fonte: Dados primários provenientes de questionário.

A partir das unidades descritas no Quadro 2, elaboramos as categorias representativas dessas unidades e que foram codificadas por I1, I2, I3, I4 e I5 - que significam - categorias emergentes das unidades imediatas - por isso I (imediatas) e que são em número de cinco - 1 a 5 .

Em seguida relacionamos - no Quadro 3 - como essas unidades foram acomodadas nas categorias.

\section{Quadro 3 - As categorias construídas a partir das unidades de análise imediatas.}

\begin{tabular}{|c|c|}
\hline Categorias & Unidades de análise \\
\hline \multirow{6}{*}{ I1 - O erro como contributo ao aprendizado. } & Promove reflexão. \\
\hline & Promove mobilização. \\
\hline & Promove aprendizado. \\
\hline & $\begin{array}{l}\text { Possibilita enxergar e agir } \\
\text { conscientemente sobre a causa do erro. }\end{array}$ \\
\hline & Motivação para saber a causa do erro. \\
\hline & O erro como uma oportunidade. \\
\hline I2 - O erro como etapa na construção do conhecimento. & O erro como uma hipótese rejeitada. \\
\hline \multirow{2}{*}{ I3 - Ganhos extra-matemáticos a partir do erro. } & Conscientização (tenho que estudar). \\
\hline & Transcendência: "linkou" com a vida. \\
\hline
\end{tabular}


I4 - A carga emotiva o erro. Gera emoção negativa.

I5 - O erro irrefletido.

Ênfase no resultado.

Uso de "chavão".

Fonte: dados primários

A seguir apresentamos algumas considerações que auxiliaram na construção dessas categorias, assim como interpretações que motivaram essas convergências e justificam os resultados obtidos desse processo.

Categoria I1 - O erro como contributo ao aprendizado. Esta é a categoria que apresentou maior frequência. Vinte e dois estudantes relatam atitudes assumidas a partir da elaboração do erro, que contribuem para o aprendizado. Dentre os registros apresentados é possível identificar essas atitudes destacadas por eles:

- Promove reflexão -

"[...] se reflito neles (referindo-se aos erros), aprendo". (A25)

"[...] refletir sobre como deveria ter feito". (A26)

- Promove mobilização -

"[...] ajuda a buscar o motivo do erro". (A26)

"Com o erro a gente busca e se interessa mais". (A24)

- Favorece o aprendizado -

"[...] aprendo explicando meu erro e refazendo certo". (A29)

"[...] aprendo mais profundamente". (A18)

“[...] eu achava que não adiantava estudar Matemática, pois nunca iria aprender, mas esse ano quando tive oportunidade de ver e corrigir meus erros fui aprendendo [...]". (A15)

"Quando se compara o erro ao que deveria ter sido realizado, o cérebro guarda a imagem da comparação". (A21)

"O erro existe para corrigir o que a pessoa não aprendeu". (A35)

"Acho que ele (o erro) contribui ricamente em nosso aprendizado". (A37)

- Possibilita enxergar e agir conscientemente sobre a causa do erro "[...] vejo as bobagens que cometi e aprendo a não errar da próxima vez". (A8) 
"[...] descubro minha dificuldade". (A18)

"Compreendo e entendo cada erro cometido e procuro praticar". (A15)

- Motivação para saber a causa do erro -

"[...] é a partir dele (referindo-se ao erro) que tento buscar a resposta correta e é aí que aprendo aquilo que havia errado." (A23)

"[...] não poderia saber onde estou "fraca" (grifo do aluno) para poder melhorar". (A13)

- O erro como uma oportunidade -

“[...] com o erro você tem a oportunidade de aprender e melhorar [...]". (A27)

"[...] esse ano quando tive oportunidade de ver e corrigir meus erros fui aprendendo [...]". (A15)

"Você tem oportunidade de saber o que não sabia". (A28)

Categoria I2 - O erro como uma etapa da construção do conhecimento. Cinco estudantes argumentaram sobre o erro como sendo uma tentativa, podendo ser entendido como hipótese adotada, ainda que provisoriamente, um meio para se alcançar um objetivo.

- O erro como hipótese a ser rejeitada -

"[...] quando me deparo com o erro eu o observo de todos os ângulos e me faz perceber que, talvez, deveria ter feito algo diferente para que este não ocorresse". (A14)

"Uso o meu erro como ponta-pé [...]". (A10)

"Aprendo uma forma de não realizar a questão". (A32)

"Uma forma de não mais seguir aquele método para tal coisa". (A5)

Categoria I3 - Ganhos extra-matemáticos a partir do erro. Nesta categoria seis estudantes citam benefícios que transcendem o ambiente escolar e se traduzem em ganhos para a formação cidadã.

- Conscientização (tenho que estudar) -

“[...] se eu for atrás e buscar saber [...] fará com que eu não caia no mesmo erro". (A16)

"Posso tentar novamente e dar o meu melhor". (A6) 
- Transcendência: "linkou" com a vida -

"[...] a partir do erro você aprende a se esforçar cada vez mais podendo ser alguém bem sucedido na vida". (A30)

"[...] alguns deles me levaram a ver e refletir na minha vida pessoal". (A15)

Categoria I4 - A carga emotiva do erro. Seis estudantes citam a forte relação que o erro provoca no equilíbrio emocional.

- Gera emoção negativa -

“[...] às vezes nos proporciona desânimo". (A34)

"O erro te deixa muito pra baixo". (A2)

"Odeio errar". (A16)

Categoria I5 - O erro irrefletido. Nesta categoria estão agrupadas as respostas que evidenciam uma preocupação imediatista, ou respostas dadas sem muita reflexão, seja para simples melhoria da nota ou para preencher o questionário solicitado.

- Ênfase no resultado (melhorar nota) -

“[...] tenho oportunidade de refazer a prova". (A7)

"Poderei acertar o que errei fazendo a prova novamente". (A10)

- Uso de "chavão" -

"É errando que se aprende". (A29 e A33)

Ao retomarmos Bardin (2004) e nos depararmos com a seguinte afirmação: a análise de conteúdo fornece meios capazes de dizer não à ilusão da transparência, distanciando-nos dos perigos da compreensão espontânea e ajudando-nos a transcender para além do significado imediato. Vemos a possibilidade de retornarmos aos dados em busca de outras interpretações.

$\mathrm{Na}$ tentativa de aprofundar o olhar para significações outras que possam estar presentes nos depoimentos, em segundo plano, lançamos mão de deduções lógicas e das possibilidades que o convívio diário com esses estudantes nos proporciona. Construímos, então, um segundo grupo de unidades de análise que abarcam algumas significações decorrentes de nossa leitura do que subjaz às informações imediatas.

Esta segunda etapa requereu um olhar mais aprofundado, decorrente, por consequência, do primeiro processo de categorização. Neste caso as unidades elen- 
cadas não estão à vista, elas são frutos de correlações percebidas por meio de intensa impregnação com os dados proveniente de leituras e releituras.

Estas categorias surgiram como "flashes" (MORAES e GALIAZZI, 2007) sinalizando a possibilidade de conexões lógicas, consistentes e mais aprofundadas entre os significados, que despontam após certo grau de 'imersão' nos dados disponíveis.

Em nosso caso foram construídas a partir de relações não percebidas à primeira vista. Exemplificamos tal situação com o fato de que apesar de um grande número de estudantes citarem que o erro é um amigo do aprendizado, deixam transparecer em seus depoimentos que possuem algum grau de aversão ao erro. Isto também pode ser ratificado com as diversas manifestações que revelam traumas em relação ao erro. Que tipo de parceiro seria o erro para ser tão pouco apreciado pelos estudantes? Que aspectos subjazem a esta questão? Vemos nisto, o despontar de um tema que merece uma investigação cuidadosa e aprofundada, que já está em curso, contudo não é o foco deste artigo.

Constatamos que há uma riqueza de informações e detalhes a respeito do erro que estão ocultos ao imediatamente revelado. A análise de conteúdo ajuda a afastar as 'cortinas' e penetrar num universo que pode ser revelador e contribuir para a compreensão do fenômeno pesquisado.

Deste movimento investigativo frutificaram seis novas unidades de análise, que chamaremos de 'subjacentes' e que estão descritas no Quadro 4.

\section{Quadro 4 - Unidades de análise subjacentes.}

\begin{tabular}{ll}
\hline Unidades de análise & Alunos depoentes \\
\hline Revela trauma em relação ao erro. & A2, A3, A7, A12, A14 \\
\hline O despreparo como causa real do erro. & A17, A20, A23, A32, A34, A36 \\
\hline Tem ciência de como deve estudar. & A5, A6, A7, A8, A9, A12, A16, A28 \\
\hline Respondeu "parceiro", mas repele o erro. & $\begin{array}{l}\text { A20, A23, A24, A25, A26, A32, A34, A1, A14, } \\
\text { A16, A26, A27, A28, A30, A31 }\end{array}$ \\
\hline Oportunidade com vistas ao resultado. & A2, A7, A10, A25, A31, A33 \\
\hline Oportunidade com vistas ao aprendizado. & A1, A3, A12, A13, A14, A15, A19, A27, A28, \\
& A32 \\
\hline
\end{tabular}

Fonte: Dados primários.

A partir destas unidades foi possível constituir as seguintes categorias: 


\section{Quadro 5 - As categorias construídas a partir das unidades de análise subjacentes.}

\begin{tabular}{lll}
\hline Categorias & Unidades de análise & Alunos depoentes \\
\hline \multirow{3}{*}{$\begin{array}{l}\text { S1 - O erro como fator } \\
\text { emocional. }\end{array}$} & $\begin{array}{l}\text { Revela trauma em relação ao } \\
\text { erro. }\end{array}$ & A23, A3, A7, A12, A14 \\
\cline { 2 - 3 } & $\begin{array}{l}\text { Respondeu “parceiro", mas } \\
\text { repele o erro. }\end{array}$ & $\begin{array}{l}\text { A1, A14, A16, A20, A23, A24, } \\
\text { A25, A26, A32, A34, A26, } \\
\text { A27, A28, A30, A31 }\end{array}$ \\
\hline \multirow{3}{*}{$\begin{array}{l}\text { S2 - O erro como uma } \\
\text { máscara. }\end{array}$} & $\begin{array}{l}\text { O despreparo como causa real } \\
\text { do erro. }\end{array}$ & $\begin{array}{l}\text { A17, A20, A23, A32, A34, } \\
\text { A36 }\end{array}$ \\
\cline { 2 - 3 } & $\begin{array}{l}\text { Tem ciência de como deve } \\
\text { estudar. }\end{array}$ & $\begin{array}{l}\text { A5, A6, A7, A8, A9, A12, } \\
\text { A16, A28 }\end{array}$ \\
\hline \multirow{2}{*}{$\begin{array}{l}\text { S3 - As “oportunidades" do } \\
\text { erro. }\end{array}$} & $\begin{array}{l}\text { Oportunidade com vistas no } \\
\text { resultado. }\end{array}$ & A2, A7, A10, A25, A31, A33 \\
\cline { 2 - 3 } & $\begin{array}{l}\text { Oportunidade com vistas no } \\
\text { aprendizado. }\end{array}$ & $\begin{array}{l}\text { A1, A3, A12, A13, A14, A15, } \\
\text { A19, A27, A28, A32 }\end{array}$ \\
\hline
\end{tabular}

Fonte: Dados primários

Categoria S1 - O erro como fator emocional. Nesta categoria estão inseridos todos os estudantes que manifestaram, mesmo que nas entre linhas, algum tipo de aversão, seja na forma de trauma, seja na forma de ódio, em relação ao erro. Muitos o fazem de forma aberta, outros deixam transparecer na construção das frases.

Em geral, no ambiente escolar, o erro é considerado da mesma forma que na sociedade: algo indesejável, uma manifestação de falta de sabedoria, ou até mesmo falta de aptidão para aprender matemática e o pior, passível de punição. Talvez isto ajude a esclarecer a forte implicação emocional relacionada ao erro.

Silva e Salvi (2010) argumentam que no ensino e aprendizado da Matemática, em geral, associa-se o erro à incompetência. Esta regra é válida entre os estudantes, na relação professor-aluno e também na relação aluno-professor, uma vez que esperam do professor exemplo de desempenho em cálculos e raciocínios, essa expectativa de 'perfeição' contribui para o fortalecimento de que o erro está aliado à incompetência, tornando-o indesejado. 
Dos dezenove estudantes incluídos nessa categoria, oito estudantes citaram, de imediato, que vêem o erro como parceiro, no entanto o repelem fortemente em seu discurso. Fato esse que compromete ou contamina a forma de encararmos o erro e o coloca na situação de um desafio a ser superado no âmbito educacional.

- Revela trauma em relação ao erro -

"O erro te deixa meio pra baixo". (A2)

"Se eu aprendesse com o erro seria fácil, mas não consigo. Quando erro dá uma vontade de desistir. Parece que não vai pra frente". (A4) "Odeio errar". (A16)

- Respondeu 'parceiro', mas repele o erro -

"[...] desde que a pessoa não volte a cometer os mesmos erros". (A1)

"[...] que eu não caia no mesmo erro duas vezes". (A16)

"Melhorar para não errar mais". (A27)

“[...] o melhor é saná-lo por completo". (A34)

Categoria S2 - O erro como uma máscara. Observamos que muitos estudantes revelam em seus depoimentos que se tivessem estudado com seriedade e se preparado adequadamente para a prova, fazendo revisão dos conteúdos propostos, poderiam evitar muitos dos erros cometidos. Em geral, assumem essa postura depois de receberem a devolutiva da prova e tomar contato com seus erros.

$\mathrm{Na}$ verdade muitos reconhecem que poderiam evitar o erro se tivessem se dedicado o necessário.

- O despreparo como causa real do erro -

"[...] quando erramos percebemos que não estávamos preparados o suficiente". (A17)

“Ás vezes despreparo, não estudamos [...]”. (A20)

"Se errei quer dizer que não estou preparada para resolver tal situação [...]". (A36)

- Tem ciência de como deve estudar-

"Depende de como quero reagir [...] posso dar o meu melhor". (A6) "É preciso atenção redobrada, com isso poderei me aperfeiçoar e ficar mais "esperta" (grifo da aluna)". (A36) 
Categoria S3 - As oportunidades do erro. Uma análise mais cuidadosa revelou que os estudantes atribuem o termo oportunidade ao erro sob duas conotações: há um grupo que manifesta a preocupação tão somente em relação à oportunidade de refazer a prova para recuperação da nota e um grupo que associa o termo a um objetivo mais amplo, no qual revela o desejo de obter um aprendizado mais significativo a partir da elaboração do erro.

- Oportunidade com vistas no resultado -

"Buscar meios de achar a resposta certa". (A2)

"Como temos a chance de fazer o relatório [...] poderei acertar o que errei”. (A10)

"Tenho a oportunidade de refazer, uma segunda chance". (A7)

- Oportunidade com vistas no aprendizado -

"[...] ele (referindo-se ao erro) se tornou útil não como fonte de recuperação de nota, mas como fonte de fixação de algo que geralmente não buscamos". (A1)

"Os erros devem ser corrigidos como motivo de superação e conhecimento novo adquirido". (A14)

"Você tem oportunidade de saber o que não sabia". (A28)

Estas categorias expressam as compreensões dos pesquisadores no momento de agrupar as unidades de análise encontradas no corpus da pesquisa e ancoradas por meio de recortes, depois de recursivas idas e vindas ao texto original (questão cinco do questionário).

A seguir tecemos algumas considerações sobre as compreensões a que essa análise dos depoimentos sobre os erros nos remete.

\section{Considerações finais}

Cabe destacar que nem todos os registros referentes a cada categoria foram aqui relacionados, contudo são considerados, em sua totalidade, para a construção das conclusões e resultados a que chegamos.

Experimentamos, constatamos e assumimos a análise de conteúdo como uma metodologia e um processo exploratório dos dados com a intenção de fazê-los 'falar' em um nível mais imediato a princípio, com o olhar voltado para a possibilidade de encontrar informações subjacentes; estas sim: reveladoras, articuladas e consistentes, reservadas ao movimento de transcendência dos liames da leitura superficial. 
Nesta pesquisa dividimos as categorias em dois grupos: as imediatas, que surgem das interpretações preliminares, ou seja, colocam-se como evidentes no processo de manipulação e impregnação dos dados e as subjacentes que surgem como 'flashes' sinalizando a possibilidade de conexões lógicas e mais aprofundadas entre os significados, que despontam após certo grau de 'imersão' nos dados disponíveis.

Dentre as categorias imediatas observamos que I1 - o erro como contributo ao aprendizado; I2 - o erro como uma etapa na construção do conhecimento; I3 - ganhos extramatemáticos a partir do erro; e que revelam aspectos positivos em relação ao erro, que nos serve de motivação para apostarmos que o erro, traz em si, grande potencial para o aprendizado, podendo contribuir de forma eficaz no desenvolvimento cognitivo e, também, com a formação cidadã dos estudantes.

Argumentamos, ainda, que há significativas vantagens à compreensão do conteúdo matemático quando o próprio erro cometido pelo estudante é usado como mote para deflagrar novas situações de aprendizagem. O que está presente em vários dos depoimentos que geraram as unidades de análise que compõem a categoria I1.

Com relação à unidade de análise em que o erro possibilita enxergar e agir conscientemente sobre sua causa, as declarações, relativas a ela, revelam que inserir o erro como estratégia para o aprendizado pode desencadear um processo de catarse no indivíduo, favorecendo um aprendizado consciente. Assumimos como catarse a idéia defendida por Gasparin (2007, p. 130) de que: catarse é o momento em que ocorre a síntese mental por parte do educando dos conteúdos trabalhados. Essa síntese é expressa quando compreende e disserta sobre aquele conteúdo, mostrando que o mesmo foi assimilado e auxiliou na transformação de seus conceitos prévios. Três estudantes revelam indicativos que alcançaram a catarse ao completarem o percurso do preenchimento do relatório de reflexão sobre os erros.

É relevante destacar, também, o fato de quatro estudantes perceberem o erro como etapa na construção do conhecimento o que nos dá subsídios para afirmar que o ato de errar significa ousar, abrir caminhos e envolve um processo de esforço mental para criar estratégias de ação com vistas a alcançar um objetivo. Tal esforço deve ser desconsiderado? Simplesmente descartado? Não há nada nele que possa contribuir para o crescimento cognitivo do estudante?

Silva e Salvi (2010) argumentam que no 'percurso' delineado pelos estudantes enquanto desenvolvem seu raciocínio na tentativa de responder uma questão, em muitos momentos, o erro se manifesta como uma etapa pertinente ao processo de construção da resposta. De alguma maneira a forma como registra e o que registra enquanto caminho para a construção do raciocínio, ainda que equivocada, tem algo a revelar sobre o aprendizado dos estudantes. Se for dada a eles a oportunidade de 
confrontar-se com seus erros podem 'enxergá-los', refletir sobre eles e superá-los; gerando ganho real no que diz respeito ao aprendizado.

As categorias I4 - a carga emotiva do erro e I5 - o erro irrefletido, revelam que há pré-conceitos que precisam ser re-elaborados a fim de podermos explorar os benefícios que o erro pode oferecer.

É relevante considerar, investigar e investir na compreensão da relação que há entre erro e emoções. Infelizmente, só constatamos a ocorrência de emoções negativas relacionas ao erro e sem dúvida, esse feito exerce influência no aprendizado e consequente desempenho dos estudantes.

As categorias subjacentes que emergiram no processo revelam que o fator emocional intrínseco ao erro é maior do que parece à primeira vista, pois pode se apresentar de forma velada e desponta como uma questão que merece pesquisa e respostas.

Essas categorias revelam, também, que alguns estudantes poderiam melhorar seu desempenho nas provas, pois reconhecem que se apresentam para a prova sem o devido preparo, procedimento não esperado para quem está prestes a ingressar na universidade, pois sabem como e quanto precisam estudar. Temos aqui outra questão que merece ser investigada: o que está impedindo esses estudantes de se prepararem adequadamente para as provas?

Na continuidade deste movimento interpelador, nos deparamos com a categoria $\mathrm{S} 3$ que traz à tona outras perguntas que nos movem à reflexão. Qual a perspectiva de futuro de um estudante do Ensino Médio? É importante refletirmos a esse respeito, pois o argumento, frequentemente usado por professores, ao justificarem a importância do aprendizado e na tentativa de motivar os estudantes a se comprometerem com o estudo de determinado conteúdo é que será importante para o futuro. O que é futuro para um estudante de "terceirão" (última série do Ensino Médio)? Como convencer tais alunos da importância de um aprendizado consistente? Os dados desta pesquisa apontam que a primeira - e porque não dizer a real - preocupação de muitos estudantes está em conquistar e exibir uma nota satisfatória.

Este é um desafio que exige reflexão, sob o risco de comprometermos o desenvolvimento efetivo das potencialidades cognitivas dos estudantes.

Acreditamos que esta pesquisa possibilitou esclarecimentos e contribuições que asseguram a importância de trazermos o erro para o palco das discussões sobre o aprendizado, também evidencia e confirma que o erro tem, de fato, muito a nos ensinar. Não somente aos estudantes no que tange ao cognitivo e ao emocional, mas também aos educadores matemáticos ao ousarem explorar os erros de seus alunos convertendo-os em situação de ensino e possibilidade de aprendizado. Cabe, ainda, na continuidade dessa investigação, verificar como esses professores observam esses erros e que percepções apresentam sobre eles. 


\section{Referências}

ABAGNANO, N. Dicionário de Filosofia. 5 ed. Revista e ampliada. São Paulo. Martins Fontes, 2007.

BALDINO, R. R.; CABRAL, T. C. B. Erro do significado ou significado do erro. Boletim GEPEM, n. 35, pp. 9-41. Rio de Janeiro, 1999.

BARDIN, L. Análise de conteúdo. Lisboa: Edições 70, 1977, 3 ed., 2004.

BERTONI, N. O erro como estratégia didática. Campinas: Papirus, 2000.

BURIASCO, R. L. C. Algumas considerações sobre avaliação educacional. In: Estudos em avaliação Educacional, São Paulo, n. 22, jul/dez, 2000.

BURIASCO, R. L. C. et al. Avaliação como prática de Investigação (alguns apontamentos). Bolema, ano 22, n. 33, pp. 69-96. Rio Claro, SP, 2009.

CURY, H. N. Análise de erros: o que podemos aprender com as respostas dos alunos. Belo Horizonte: Autêntica. 2007.

CURY, H.; KONZEN, B. Uma aplicação de jogos na análise de erros em educação matemática. Revemat: Revista eletrônica de educação matemática, v.2, n.1, 2007.

DALTO J. O.; BURIASCO R. L. C. Problema proposto ou problema resolvido: qual a diferença? Educação e Pesquisa, v.35, n.3, pp. 449-461, set/dez, São Paulo, 2009.

DAVIS, C.; ESPÓSITO, Y. O Papel e a Função do Erro na Avaliação Escolar. Revista Brasileira de Estudos Pedagógicos, Brasília, v.72, n.171, pp. 196-206, 1991.

ESTEBAN M. T. O que sabe quem erra? Reflexões sobre avaliação e fracasso escolar. 3ed. Rio de Janeiro: DP\&A, 2002.

GASPARIN,J. L. Uma didática para a pedagogia Histórico-crítica. 4 ed. rev. Campinas: Autores Associados, 2007. (Coleção educação contemporânea).

KISTEMANN, M. A. O Erro e a Tarefa Avaliativa em matemática: uma abordagem qualitativa. Anais do X EBRAPEM - Encontro Brasileiro de Pesquisa em Educação Matemática. FaE/UFMG, 2006. CD-ROM. 
LA TAILLE, Y. de. O Erro na Perspectiva Piagetiana. In: AQUINO, J. G. (Org.). Erro e Fracasso na Escola: alternativas teóricas e práticas. São Paulo: Summus, 1997.

LUCKESI, C. C. Avaliação da Aprendizagem Escolar. São Paulo: Cortez, 1996.

LÜDKE, Menga; ANDRÉ, Marli E. D. A. Pesquisa em educação: abordagens qualitativas. São Paulo: EPU, 1986.

MACEDO, L. de. Para uma Psicopedagogia Construtivista. In: ALENCAR, E. S. de. Novas Contribuições da Psicologia aos Processos de Ensino e Aprendizagem. São Paulo: Cortez, pp. 121-140, 1995.

MORAES, R.; GALIAZZI, M. C. Análise textual discursiva. Ijuí: Ed. Unijuí, 2007.

PERRENOUD, P. Dez novas competências para ensinar. Porto Alegre: Artes Médicas Sul, 2000.

SILVA, M. C.; BURIASCO, R. L. C. Análise da produção escrita em Matemática: algumas considerações. Ciência \& Educação, v.11, n.3, pp. 499-512, 2005.

SILVAA. G. O.; SALVI, R. F. É possível aliar o erro ao processo de aprendizagem? Um desafio em Educação Matemática. Anais eletrônicos do VIII ANPEDSUL Encontro de Pesquisa em Educação da Região Sul, 2010. CD-ROM.

Submetido em setembro de 2011 Aprovado em janeiro de 2012 